\title{
Nerve Growth Factor-induced Hyperalgesia in the Neonatal and Adult Rat
}

\author{
Gary R. Lewin, Amy M. Ritter, ${ }^{a}$ and Lorne M. Mendell \\ Department of Neurobiology and Behavior, SUNY at Stony Brook, Stony Brook, New York 11794
}

Recently, we have shown that the interaction between NGF and sensory neurons in early postnatal periods is restricted to nociceptive afferents (Ritter et al., 1991; Lewin et al., 1992a; Ritter and Mendell, 1992). Here we show that administration of excess NGF to neonatal or mature animals can lead to a profound behavioral hyperalgesia. Neonatal NGF treatment (postnatal day $0-14$ ) resulted in a profound mechanical hyperalgesia that persisted until the animals had reached maturity ( 6 weeks of age). This hyperalgesia could be explained by an NGF-mediated sensitization of A $\delta$ nociceptive afferents to mechanical stimuli. This peripheral sensitization wore off with a time course similar to that of the behavioral hyperalgesia. Treatment of animals from the second postnatal week until 5 weeks of age (juveniles) led to a very similar behavioral hyperalgesia; however, there was no corresponding sensitization of A $\delta$ nociceptors to mechanical stimuli. Finally, one group of adult animals ( 5 weeks old) was treated daily with single injections of NGF for between 1 and $4 \mathrm{~d}$. Within $24 \mathrm{hr}$ after the first NGF injection these animals developed a mechanical hyperalgesia of the same magnitude seen after neonatal and juvenile NGF treatments. No sensitization of A $\delta$ nociceptive afferents was observed in these animals. In addition to the mechanical hyperalgesia, the animals also developed a heat hyperalgesia after one injection of NGF. The heat hyperalgesia was apparent within 15 min after the injection; however, signs of mechanical hyperalgesia were not seen until $6 \mathrm{hr}$ after the injection. In conclusion, it appears that the NGF-induced mechanical hyperalgesia is brought about by different mechanisms in neonatal and adult rats. Furthermore, in adult animals the NGFinduced mechanical and heat hyperalgesia also appear to be attributable to two different mechanisms. The mechanical hyperalgesia may be due to central changes (see Lewin et al., 1992b), whereas the heat hyperalgesia is likely to result at least in part from the sensitization of peripheral receptors to heat.

IKey words: neurotrophism, pain, sensitization, hyperalgesia, sensory neurons, neurophysiology]

\footnotetext{
Received July 28, 1992; revised Oct. 5, 1992; accepted Nov. 23, 1992.

We thank Dr. Norbert Kremer for help in the isolation of the NGF and Dr. Simon Halegoua for the use of his facilities for this purpose, and Dr. Martin Koltzenburg for his helpful comments on the manuscript. A.M.R. was supported in part by Training Grant MH 18018 (NIMH). This research was supported by a subproject of NIH Program Project Grant PO1 NS14899. Additional support was derived from NIH RO1 NS 16966 to L.M.M. (Javits Neuroscience Award).

Correspondence should be addressed to Lorne M. Mendell at the above address.

aPresent address: Laboratory of Neural Control, NINDS/NIH, Building 36, Bethesda, MD 20892.
}

Copyright (c) 1993 Society for Neuroscience 0270-6474/93/132136-13\$05.00/0
The best-characterized physiological role for NGF during development is that of a survival factor for sympathetic and sensory neurons (Barde, 1989). However, sensory neurons require NGF for survival only at relatively early developmental stages (Gorin and Johnson, 1980; Johnson et al., 1980; Schwartz et al., 1982; Goedert et al., 1984; Yip et al., 1984). In the rat this dependence on NGF for sensory neuron survival appears to end around postnatal day 2 (Lewin et al., 1992a). The numbers and types of neurons that require NGF for survival change from the prenatal to the postnatal period in rats; almost all sensory neurons die if exposed to antisera to NGF before birth, whereas only about $20 \%$ of all dorsal root ganglion (DRG) cells (mostly small cells) appear to be dependent on NGF postnatally (Johnson et al., 1980; Yip et al., 1984; Lewin et al., 1992a). Under most circumstances it appears that NGF is particularly important for small-diameter peptide-containing neurons (for reviews, see Otten, 1984; Lindsay, 1988). Anti-NGF treatments in the pre- or postnatal period can lead to reductions in the number of substance P-containing neurons in the DRG (Otten et al., 1980; Goedert et al., 1984), and evidence from in vitro and in vivo studies suggests that calcitonin gene-related peptide (CGRP) may also be regulated by NGF levels (Lindsay et al., 1989; Inaishi et al., 1992). Conversely, NGF treatments can lead to large increases in the peptide content of DRG neurons (Goedert et al., 1980; Kessler and Black, 1980; Otten and Lorez, 1983; Lindsay et al., 1989) and also reverse the neurotoxic actions of capsaicin when this is administered to neonatal rats (Otten et al., 1983). Thus, NGF appears to be particularly important for small peptidergic neurons in early postnatal periods. These neurons are usually assumed to be nociceptive. However, this does not necessarily follow from their size or peptide content. Smalldiameter sensory neurons may have low-threshold sensory receptors (see Burgess and Perl, 1973, for review), and a direct link between a sensory neuron's peptide content and its nociceptive physiology has yet to be proven (see Leah et al., 1985).

Changes in the behavioral response of animals to nociceptive stimuli following neonatal antisera treatments have been observed (Aloe et al., 1981; Urschel et al., 1991), but in these cases substantial cell death had almost certainly occurred (Johnson et al., 1980; Goedert et al., 1984; Hulsebosch et al., 1987). Thus, it is not entirely clear if NGF regulates nociceptive function in ways other than promoting cell survival during development.

Even less is known about the actions of NGF in the mature animal, where deprivation of this factor does not lead to any cell death (see Johnson et al., 1986, for review). Nonetheless, in adult animals NGF continues to be synthesized in peripheral tissucs and retrogradely transported to sensory neuron cell bodies (Stockel et al., 1975; Goedert et al., 1980; Thoenen and 
Barde, 1980). It appears that NGF retains its specificity for some small peptidergic neurons, as high-affinity NGF receptors are found predominantly in these cells (Verge et al., 1989). In adult animals it is known that small-diameter peptidergic neurons certainly do not constitute a physiologically homogeneous group (Leah et al., 1985).

Many afferent types can be identified in the DRG based on their target, modality, and somatic spike characteristics (Burgess and Perl, 1973; Rose et al., 1986; Koerber et al., 1988; Ritter and Mendell, 1992). Recently, we have shown that some aspects of the somatic spikes of myelinated cutaneous high-threshold afferents appear to be specifically regulated by NGF (Ritter and Mendell, 1992). However, it was not clear whether this regulation occurs in the early postnatal period or in the mature animal (Ritter et al., 1993).

Recently, we have been examining the physiological consequences for sensory neurons of trophic factor deprivation during development and in maturity. We have established that NGF has an important role in maintaining the phenotype of myelinated nociceptors in neonatal rats (Ritter et al., 1991). Thus, by treating animals with heterologous antibodies to NGF during postnatal day 4 (PND4) and PND11, most myclinated nociceptors in the rat sural nerve take on the phenotype of D-hairs (low-threshold $A \delta$ afferents). NGF deprivation produces this effect in the absence of cell death, and so it is not acting as a survival factor (Lewin et al., 1992a). The reduction in the numbers of myelinated nociceptors is accompanied, in the mature animal, by a reduction in the magnitude of antidromic vasodilatation elicited by stimulating A $\delta$ afferents (Lewin et al., 1992c), and this may be related to the fact that fewer CGRP-immunoreactive fibers are present in the skin of these animals (Tonra et al., 1992). No similar effects were seen when adult animals were treated with anti-NGF (Ritter et al., 1991).

In the present study we have investigated the effects of exogenous NGF on myelinated nociceptors in neonatal, juvenile, and adult animals. Using this approach we have provided evidence that NGF directly affects the physiological properties of nociccptive ncurons and cven certain aspects of nociceptive information transfer in the adult CNS (see Lewin et al., 1992b). We describe for the first time a highly specific behavioral hyperalgesia that is induced by NGF treatment and provide evidence that NGF may operate via more than one mechanism to bring about this state.

Some of these results have been published in short form (Lewin et al., 1991; Lewin and Mendell, 1992).

\section{Materials and Methods}

Nerve growth factor (NGF; $2.5 \mathrm{~S}$ ) was isolated from mouse submaxillary gland using the method described by Schlenker et al. (1976). SpragueDawley rats of either sex were subjected to one of four NGF treatment regimes. The first regime was to administer NGF to animals from birth to 5 weeks of age, with NGF given every day for the first $7 \mathrm{~d}(1 \mu \mathrm{g} / \mathrm{gm}$, s.c.) and then every other day thereafter. Animals given this treatment were the subjects of another electrophysiological study (Ritter and Mendell, 1992), and behavioral observations from these animals are reported here. The second regime was a neonatal treatment with NGF injected subcutaneously or intraperitoneally at a dose of $2 \mu \mathrm{g} / \mathrm{gm}$ every day from birth (designated PND 0 ) for the first $7 \mathrm{~d}$ and then every other day thereafter until PND 14. This treatment overlaps a period when the physiology of primary sensory neurons innervating skin matures (Fitzgerald, 1967; Reynolds et al., 1991) and a period of dependence on NGF for survival (Ritter et al., 1991; Lewin et al., 1992a). The third regime was designated juvenile treatment. NGF was administered at an intraperitoneal dose of $1 \mu \mathrm{g} / \mathrm{gm}$ from 2 to 5 weeks of age when the animal reaches sexual maturity. Again injections were given every day for the first $7 \mathrm{~d}$ (first injection given on PND 14) and every other day thereafter. We recognize that the animals are not mature when this treatment is started but the animal is mature when the treatment finishes, and $A \delta$ nociceptors have adult-like properties by PND 14 in the rat (Fitzgerald, 1987; Fulton, 1987). The fourth regime was to treat fully mature animals (over 5 weeks old) with NGF ( $1 \mu \mathrm{g} / \mathrm{gm}$, i.p.) every day for up to $4 \mathrm{~d}$.

Behavioral assessments of the mechanical threshold for the nociceptive flexion reflex were made in control (untreated) and in neonatal, juvenile, and adult NGF-treated animals. Thresholds were measured using calibrated von Frey hairs in awake, lightly restrained animals. Hairs of increasing force were applied to the dorsum of the foot until a consistent flexion was elicited from all regions of the dorsal foot (from toes to ankle). When a flexion was elicited in more than $80 \%$ of the von Frey hair applications (stimuli given every $30 \mathrm{sec}$ at least 10 times), this was then taken as threshold. Measurements were made in control and experimental animals every other day from PND 14 until the time of recording. The use of calibrated von Frey hairs gave consistent results in our hands with one disadvantage in this context. Not many of the von Frey hairs were calibrated for the relatively high forces needed to evoke a flexion reflex. Therefore, it was not possible to detect accurately very small changes from the baseline threshold, and this is reflected in the large standard deviation bars for control data, in Figures 1 and 2, for example. In some experiments the animals' sensitivity to noxious heat was also measured. This was done by measuring the latency for foot withdrawal from a $49^{\circ} \mathrm{C}$ water bath in awake, lightly restrained animals.

Electrophysiological recordings from single myelinated primary afferent fibers were made under urethane anesthesia $(1.25 \mathrm{gm} / \mathrm{kg}$, i.p.) after the animals had reached 5-13 weeks of age. Briefly, a laminectomy was performed to expose the entire $\mathbf{L} 5$ dorsal root and recordings were made in teased dorsal root filaments of single units driven by sural nerve stimulation as has previously been described in detail (Lewin and McMahon, 1991; Lewin et al., 1992a). In three animals treated from 0 to 5 weeks with NGF (group 1), every isolated single unit responding to sural nerve stimulation was characterized. We have previously used this technique to estimate the relative proportions of each unit type present in the sural nerve in control and experimental animals (Ritter et al., 1991; Lewin et al., 1992a). In these experiments we concentrated on elucidating the properties of cutaneous high-threshold mechanoreceptors (HTMRs) in response to various trealment regimes.

In this study we have encountered three types of cutaneous A $\delta$ HTMR. The first type is a relatively sensitive HTMR type that has a large receptive field with one or more small spots of high sensitivity (Burgess and Perl, 1967; Lynn and Carpenter, 1982). The mechanical threshold of this type of afferent was determined by finding the smallest von Frey hair needed to produce a slowly adapting discharge $(>20 \mathrm{sec})$ when applied to a sensitive spot of the receptive field. For all the units of this type, von Frey thresholds were less than $28 \mathrm{gm}$ (see Figs. 4,5 ), and in this article we have designated this type of HTMR a slowly adapting unit. In recent years it has become clear that a substantial number of nociceptors code the intensity of noxious mechanical stimulation very poorly; that is, they produce very few spikes in response to very highintensity stimuli and often fail to discharge with repeated stimulation. This type of unit has been designated "mechanically insensitive" and is present in large numbers among the $\mathrm{A} \delta$ and $\mathrm{C}$-fiber population in rat and monkey (Handwerker et al., 1991; Meyer et al., 1991; Kress et al., 1992; Lewin et al., 1992a). In this study we have subclassified these units as rapidly adapting, as they rarely discharged more a than a few spikes at the onset of very high-intensity stimulation ( $>28 \mathrm{gm}$ ). Another type of unit also designated as mechanically insensitive, is one for which no cutaneous or deep receptive field could be found. This type of unit has also been encountered by others, and is likely to be an insensitive or habituated variety of the rapidly adapting, mechanically insensitive afferents described above (see Meyer et al., 1991).

Where means are quoted in the text, they are given together with their standard deviations.

\section{Results}

NGF-induced hyperalgesia

Animals were given chronic treatments of NGF from birth until maturity ( 5 weeks) for the purposes of another study (Ritter and Mendell, 1992). It was noted that these animals were very sen- 


\section{Hyperalgesia Induced by Chronic NGF Treatment ( $0-5 \mathrm{wk})$}

Figure 1. Behavioral measurements made in 5-week-old rats treated with NGF from birth. Control measurements are taken from age+matched untreated rats. On the left, the mean threshold in grams (using calibrated von Frey hairs; see Materials and Methods) needed to evoke paw withdrawal is shown. After NGF treatment, the threshold for paw withdrawal decreased to about $10 \%$ of normal, indicating a profound mechanical hyperalgesia. The same animals appeared to be hyperalgesic to heat stimuli as well (right), as the latency for paw withdrawal was reduced to less than $50 \%$ of that seen in controls. The behavioral observations were made daily over a period of 1 week. Error bars are SDs.
Mechanical

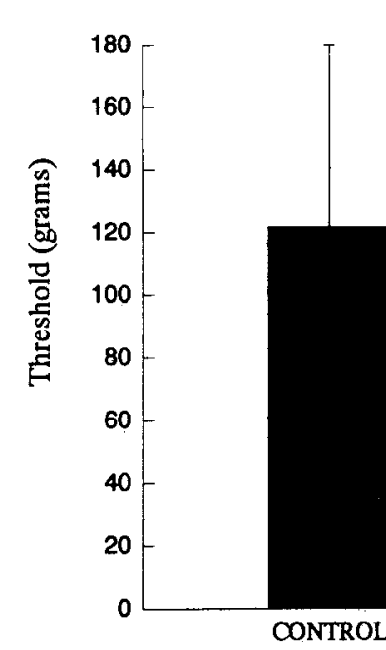

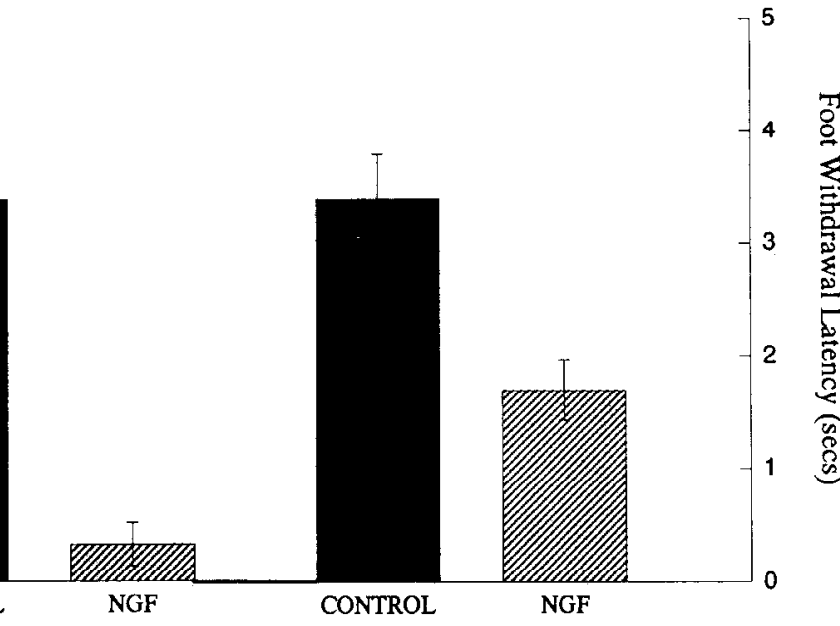

sitive to the injections compared to animals given preimmune sera or anti-NGF. Upon examination, we found that the adult NGF-treated animals were profoundly hyperalgesic to mechanical and thermal stimuli (Fig. 1). Behavioral thresholds for nociceptive flexion reflex were reduced to about $10 \%$ of control $(11.7 \pm 6.8 \mathrm{gm}$ compared to $121.6 \pm 58 \mathrm{gm}$ in control animals; ANOVA, $p<0.001)$. The reduction in the threshold needed to elicit the flexion reflex has been interpreted as hyperalgesia in these experiments for the following reasons. First, the NGFtreated animals exhibited behavior consistent with pain in response to the smaller stimuli needed to evoke the flexion reflex; for example, they vocalized and occasionally "froze" during application of the stimulus (see Ferreira et al., 1978). Second, the stimulus intensity required to elicit the reflex after NGF treatment was sufficient to activate most nociceptors but was at least two orders of magnitude higher than the threshold intensity for low-threshold mechanoreceptors. Not surprisingly, then, innocuous stimuli such as brush or touch did not evoke any aversive reactions from these animals. The animals in our study were under no apparent stress when they were handled, and in every other way their behavior appeared to be normal.

In previous studies on myelinated nociceptor function we have shown that the physiological role of NGF in neonatal and adult animals is different (Ritter et al., 1991; Lewin et al., 1992a). Therefore, in this study we have looked for behavioral hyperalgesia and its possible neural correlates after both neonatal and adult NGF treatments (see Materials and Methods). It is important to note that the hyperalgesia ohserved after these other treatments was very similar to that observed after chronic NGF treatment.

\section{$N G F$-induced hyperalgesia in neonates}

In control neonatal rats, flexion reflex thresholds increase as the animal gets older such that neonatal rats are hypersensitive to mechanical stimuli at birth (as are neonatal humans) (Fitzgerald et al., 1988). This hyperreflexia in neonates has been postulated to be due to the immaturity of interneuronal relays that regulate the threshold of the reflex (Fitzgerald et al., 1988). In this study we monitored the reflex threshold of untreated animals from the second postnatal week to 8 weeks. We found that control rats were behaviorally very sensitive to mechanical stimuli in the third and fourth postnatal week (thresholds between $10 \%$ and $20 \%$ of those of adult animals). Subsequently their reflex thresholds began to approach those of adults, and were statistically indistinguishable from them at 6 weeks (Fig. 2). Animals that had been given injections of NGF in the first 2 postnatal weeks had significantly lower reflex thresholds than controls (nested ANOVA, $p<0.05$ ) at 3, 5, 6, and 7 weeks of age. This difference was particularly impressive when the neonatally NGFtreated animals had reached maturity (6 and 7 weeks of age) (Fig. 2). Thus, neonatal NGF treatment appeared to lead to a behavioral mechanical hyperalgesia in the mature animal.

\section{Physiology of afferents in neonatally $N G F$-treated rats}

In control animals and NGF-treated animals ( $0-2$ weeks) we made recordings from single myelinated afferents activated from the sural nerve when the animals were between 5 and 13 weeks old. The physiology and incidence of $\mathrm{A} \beta$ afferents in control and neonatal NGF-treated animals appeared to be indistinguishable (Table 1). Thus, hair follicle afferents, field receptors, Pacinian corpuscle afferents, and $\mathrm{A} \beta$ HTMRs were all present in the same proportion in control and nconatally NGF-treated animals. In addition, the conduction velocity and threshold of the various $A \beta$ afferent fibers (other than $A \beta$ HTMRs) were also no different from controls (Table 1). About $30 \%$ of afferents in the $\mathrm{A} \beta$ range innervated subcutaneous structures in neonatally NGF-treated animals, which was the same as in control animals (Ritter et al., 1991; Lewin et al., 1992a). It may be noticed from Table 1, however, that the A $\beta$ HTMRs $(n=6)$ in neonatally treated animals had very low thresholds compared to the one unit found in control animals; this decrease is consistent with what was observed for A $\delta$ afferents (see below). 


\section{Duration and Extent of NGF-induced Hyperalgesia}

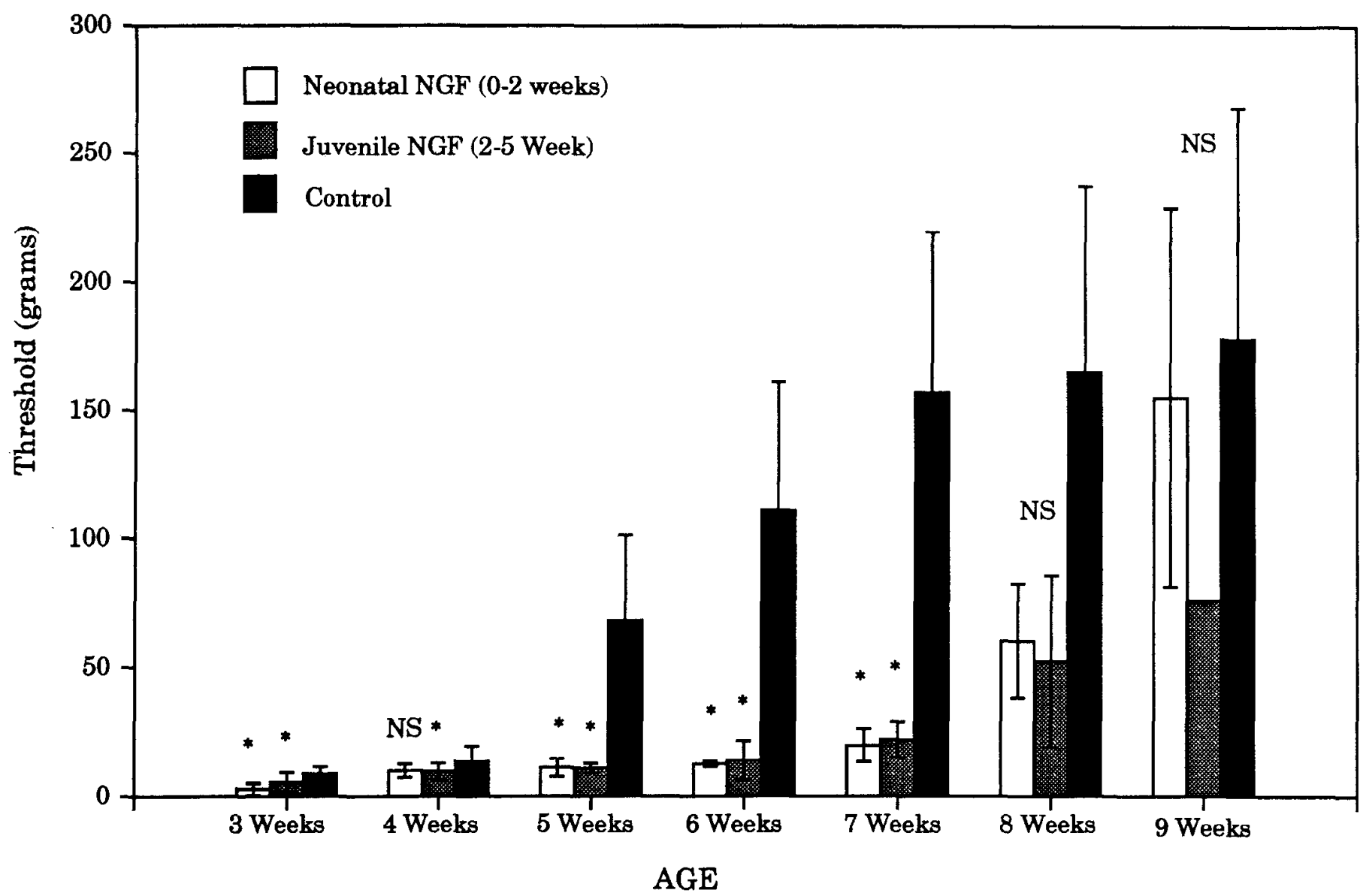

Figure 2. Serial behavioral measurements made from rats aged 3-9 weeks after neonatal and juvenile NGF treatments. Measurements of mechanica thresholds were made every day (see Materials and Methods), and the data from each group were averaged for the week. Normal rats (solid bars) have very low behavioral thresholds at 3 and 4 weeks of age. The thresholds then rise to attain near adult values at between the sixth and seventh week. After neonatal (0-2 week) NGF treatment, thresholds (open bars) were significantly lower than those of controls at 3, 5, 6, and 7 weeks (nested $\Lambda$ NOV $\Lambda, p<0.05$ ). This difference was particularly marked at 5,6 , and 7 wecks. After juvenile NGF treatment (which started at the beginning of the third week and ended at the end of the fifth week), thresholds (crosshatched bars) were also significantly lower than controls at 3 , $4,5,6$ and 7 weeks (nested ANOVA, $p<0.05$ ). In each group, measurements were made from at least three animals. The error bars are SDs.

Table 1. Physiology of $A \beta$ afferents after NGF treatment

\begin{tabular}{|c|c|c|c|c|c|c|c|c|c|}
\hline & \multicolumn{3}{|l|}{ Control $^{a}$} & \multicolumn{3}{|l|}{$\begin{array}{l}\text { Neonatal } \\
\text { NGF } \\
\end{array}$} & \multicolumn{3}{|l|}{$\begin{array}{l}\text { Juvenile } \\
\text { NGF }\end{array}$} \\
\hline & $\%$ Total & $\begin{array}{l}\text { Mean CV } \\
(\mathrm{m} / \mathrm{sec})\end{array}$ & $\begin{array}{l}\text { von Frey } \\
\text { threshold } \\
\text { (gm) }\end{array}$ & $\%$ Total & $\begin{array}{l}\text { Mean CV } \\
(\mathrm{m} / \mathrm{sec})\end{array}$ & $\begin{array}{l}\text { von Frey } \\
\text { threshold } \\
\text { (gm) }\end{array}$ & $\%$ Total & $\begin{array}{l}\text { Mean CV } \\
(\mathrm{m} / \mathrm{sec})\end{array}$ & $\begin{array}{l}\text { von Frey } \\
\text { threshold } \\
\text { (gm) }\end{array}$ \\
\hline $\begin{array}{l}\text { Hair follicle } \\
\text { afferent }\end{array}$ & $58.8 \%(30 / 51)$ & $22.9+5.3$ & $0.05+0.08$ & $57 \%(33 / 58)$ & $2.2 .2 \pm 5.1$ & $0.03 \pm 0.04$ & $67 \%(8 / 12)$ & $22.7 \pm 4.6$ & $0.07 \pm 0.13$ \\
\hline $\begin{array}{l}\text { Slowly adapting } \\
\text { (SAI and } \\
\text { SAII) }\end{array}$ & $5.9 \%(3 / 51)$ & $24.2 \pm 5.1$ & $0.07 \pm 0.0$ & $3.4 \%(2 / 58)$ & $29.3 \pm 0.7$ & $0.09 \pm 0.07$ & $0 \%$ & NA & NA \\
\hline Field & $17.6 \%(9 / 51)$ & $24.0 \pm 5.8$ & $0.19 \pm 0.2$ & $19 \%(11 / 58)$ & $24.2+6.2$ & $0.19+0.11$ & $17 \%(2 / 12)$ & $23.8 \pm 4.2$ & 0.41 \\
\hline $\begin{array}{l}\text { Pacinian } \\
\text { corpuscle }\end{array}$ & $12 \%(6 / 51)$ & $23.8 \pm 4.0$ & NA & $10.3 \%(6 / 58)$ & $26.1 \pm 5.6$ & NA & $8.3 \%(1 / 12)$ & 28 & NA \\
\hline A $\beta$ HTMR & $5.9 \%(3 / 51)$ & $20.1 \pm 4.3$ & $11.7(n=1)$ & $10.3 \%(6 / 58)$ & $17.4 \pm 1.7$ & $1.9 \pm 1.2$ & $8.3 \%(1 / 12)$ & 15.4 & $\begin{array}{l}\text { Not deter- } \\
\text { mined }\end{array}$ \\
\hline
\end{tabular}




\section{CONTROLS}

A $<9$ Weeks

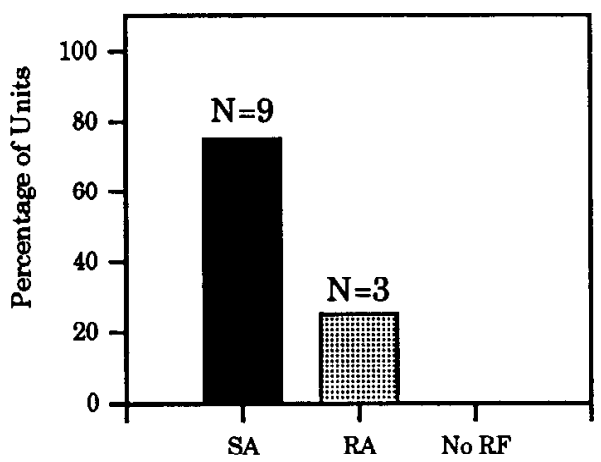

B >9 Weeks

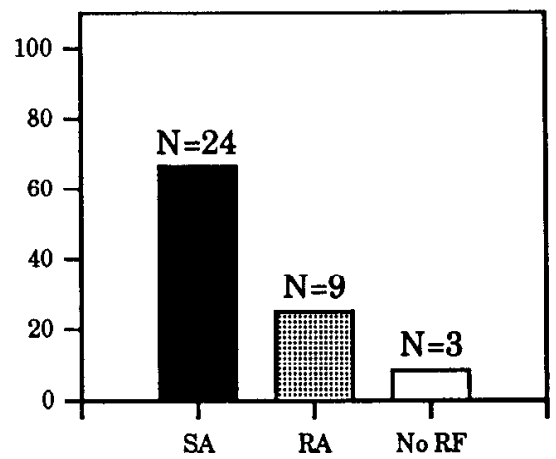

Figure 3. The proportion of slowly adapting $(S A)$, rapidly adapting $(R A)$, and silent (No $R F$ ) A $\delta$ HTMRs encountered in animals after neonatal and "adult" NGF treatments. The control data were divided into two groups: units classificd in 5-6-week-old animals $(<9$ weeks; $A$ ), and units classified in 1014-week-old animals ( $>9$ weeks; $B$ ). The proportion of the unit types was not different at these two ages. In the group in $A$, no silent units ( $N o R F$ ) were encountered, probably due to the relatively small sample as these units are rare normally. $C$ and $D$ illustrate the classification of units after neonatal NGF treatment. The first group $(C)$ was recorded in animals aged less than 9 weeks old (usually 5-6-week-old animals), and it can be seen that all the units were of the sensitive slowly adapting type. This is in marked contrast to the data obtained from control animals of the same age $(A)$. In $D$ the units were recorded from animals older than 9 weeks (usually 10-13 weeks old) and in contrast to $C$. The proportions of unit types closely resemble those seen in agematched controls $(A$ and $B$ ). $E$ and $F$ illustrate the classification of units after NGF treatment in more mature animals: $E$ is amalgamated data from juvenile NGF-treated animals and $F$ is data from adult NGF-treated animals (sec Materials and Methods). In both cases the proportions of unit types are very similar to those seen in controls. $N$ indicates the number of single units recorded.

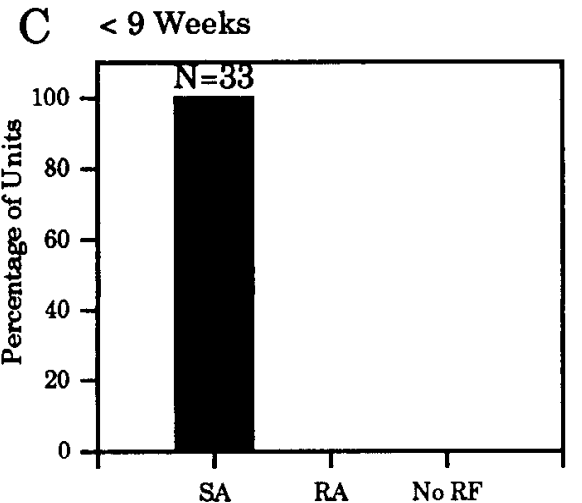

D > 9 Weeks

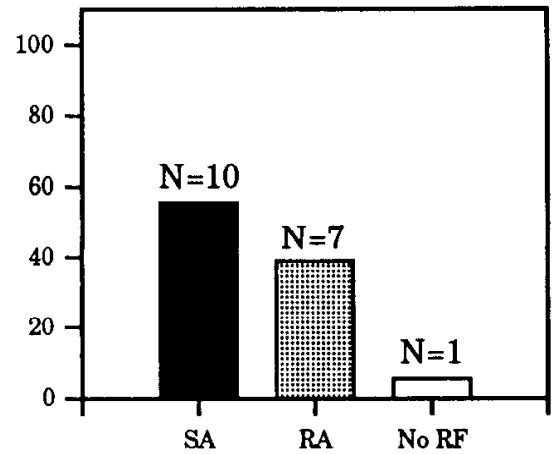

\section{"ADULT" NGF TREATMENT}

E Juvenile NGF

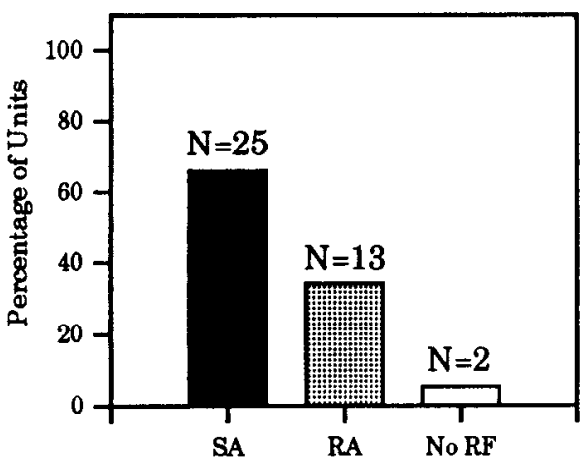

F Adult NGF

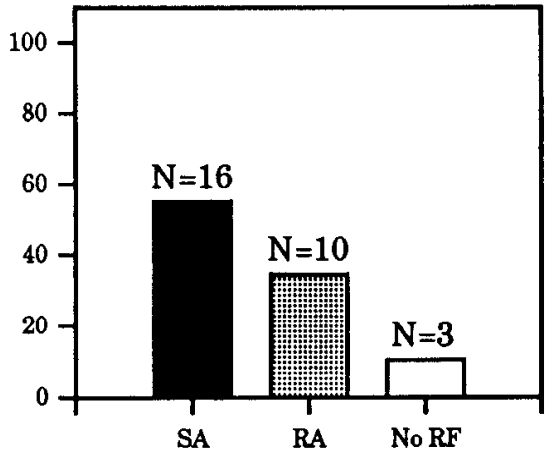

Within the A $\delta$ range (taken here as between 2 and $14 \mathrm{~m} / \mathrm{sec}$ in 5-6-week-old animals) the relative proportion of HTMRs $(38 \%)$, D-hair afferents $(35 \%)$, and deep afferents $(27 \%)$ observed after neonatal NGF treatment was not significantly different from that in controls (Rittcr ct al., 1991; Lewin et al., 1992a).

In control experiments (animals aged between 5 and 14 weeks), $69 \%$ of A $\delta$ HTMRs (33/48 fibers) activated from the sural nerve were classified as slowly adapting (see Fig. $3 A$ ), and the me- chanical threshold of these afferents ranged from 1.2 to $11.7 \mathrm{gm}$ (Fig. 4). Twelve units (25\%) were classified as rapidly adapting, and no mechanosensitive receptive field was found for the remaining three units $(6 \%)$. The control units were recorded from two groups of animals. The first were all five weeks old $(<9$ weeks in Fig. $3 A$ ), and the second were all around 13-14 weeks old ( $>9$ weeks in Fig. $3 B$ ). It can be seen that there was very little difference in the proportion of fibers classified as slowly 
adapting and rapidly adapting at the two ages. The mean mechanical threshold and receptive field area of the slowly adapting HTMRs at the two ages were also not different (Table 2). This suggests that the change in behavioral threshold observed in control animals between 5 and 9 weeks of age (Fig. 2) was not due to changes in A $\delta$ fiber thresholds (see Fitzgerald et al., 1988).

Animals treated neonatally ( $0-2$ weeks) with NGF were divided into two groups for single-unit recording. The first group of recordings was from rats between 5 and 7 weeks of age (i.e., 3-5 weeks after the end of the neonatal NGF treatment), when the animals were still behaviorally hyperalgesic to mechanical stimuli (Fig. 2). The second group of recordings was from rats between 10 and 13 weeks of age, by which point the behavioral hyperalgesia had worn off completely (data not shown, but see Fig. 2). Myelinated A $\delta$ HTMRs recorded from the former group were markedly different from those found in control animals (see Fig. 3C, Table 2). None of the 33 HTMRs studied in the younger animals displayed a rapidly adapting response to noxious mechanical stimuli. In addition, no units were sampled for which a receptive ficld could not be found. Thus, the mechanically insensitive afferents (our rapidly adapting and no receptive field categories; see Materials and Methods) had apparently disappeared in these animals. The mean mechanical threshold of HTMRs in these NGF-treated rats was $2.5 \pm 1.2 \mathrm{gm}$, compared to $4.7 \pm 2.6 \mathrm{gm}$ (data amalgamated from the two control groups) for slowly adapting HTMRs in control animals (Table 2, Fig. $4 A)(p<0.0001$, Kolmogorov-Smirnov test). This contrasts with anti-NGF treatments covering the period from PND 4 to PND 11, which leave the remaining HTMRs with mechanical thresholds approximately double those in controls (Lewin et al., 1992a; Ritter et al., 1993). Despite the change in receptor threshold, there was no significant change in the mean receptive field size of the slowly adapting HTMRs (Table $2 ; p>0.6$, MannWhitney test).

It may be noticed from Figure $4 A$ that some of the units classificd as HTMRs in the NGF-treated group had mechanical thresholds of less than $1 \mathrm{gm}$. In common with others (Lynn and Carpenter, 1982; Lewin and McMahon, 1991), we have used this as the cutoff point for designating a unit as a low- or highthreshold mechanoreceptor in normal animals. In the NGFtreated animals, however, the physiology of these afferents with thresholds less than $1 \mathrm{gm}$ was identical to normal A $\delta$ HTMRs in every other respect (e.g., in conduction velocity and receptive field characteristics).

In the second group of neonatally NGF-treated animals that had ceased to be hyperalgesic (10-13 weeks old), a total of 18 high-threshold $\mathrm{A} \delta$ afferents was examined. The HTMRs encountered in this group more closely resembled those found in control animals (Fig. 3D). Fifty-five percent were slowly adapting ( 10 of 18 ), and $39 \%$ ( 7 of 18 ) were rapidly adapting with very high thresholds $(>28 \mathrm{gm}$ ) similar to those in controls (Fig. $3 A, B)$. A mechanosensitive receptive field could not be found for the remaining unit. Thus, it appeared that neonatal NGF treatment did not lead to an irreversible loss of mechanically insensitive afferents (i.e., rapidly adapting and silent units). The slowly adapting units found in this group had mechanical thresholds that were slightly lower than those found in control animals $(3.8 \pm 2.2 \mathrm{gm})$. It can be seen from the cumulative sum shown in Figure $4 B$ that their thresholds approach those recorded from control animals and this difference was not significant (Kolmogorov-Smirnov, $p=0.32$ ). In parallel with this, we observed that these animals were no longer appreciably hyperalgesic to

\section{Thresholds of HTMRs after Neonatal NGF Treatments}

A
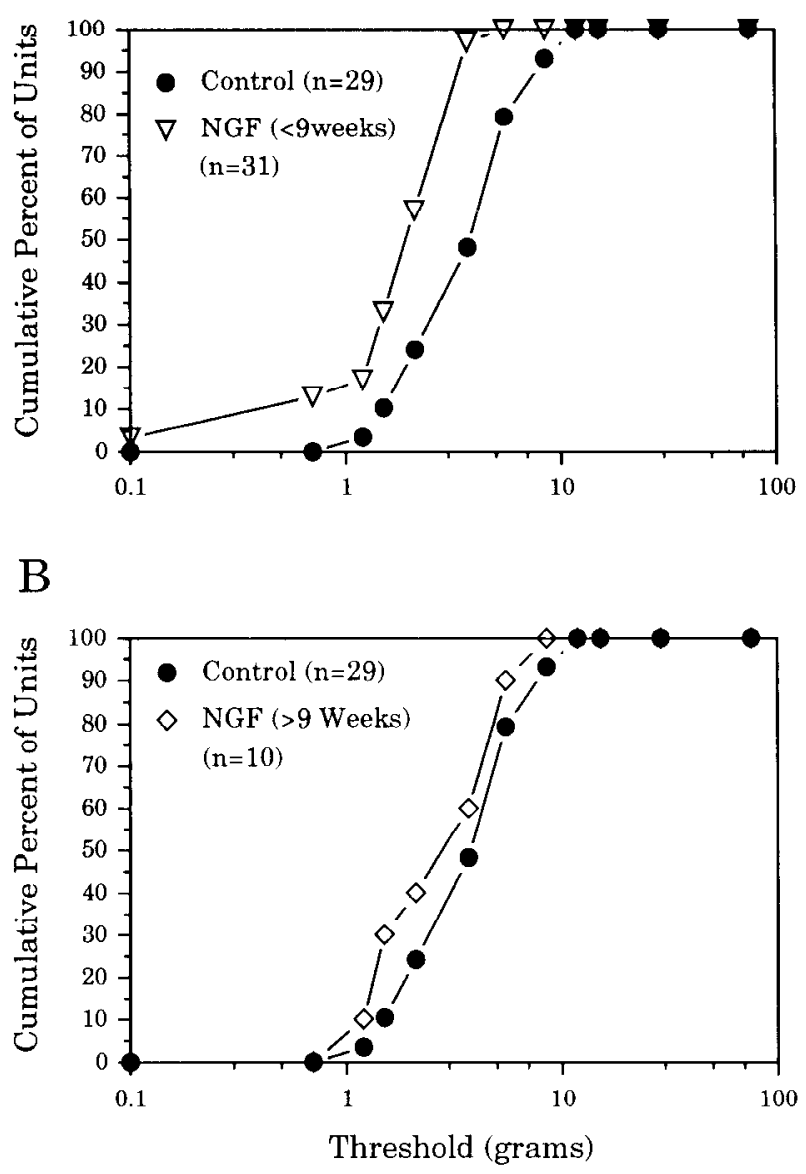

Figure 4. Cumulative sum distributions of slowly adapting HTMR thresholds in control and neonatally NGF-treated animals. In these plots, cach point along the ordinate represents the force in grams delivered to the skin by a von Frey hair. The percentage of units with thresholds at and below each von Frey hair is represented on the abscissa. Thus, $100 \%$ of the slowly adapting HTMR units had thresholds below $76 \mathrm{gm}$. In $A$ the data from control (data amalgamated from young and old animals; see Table 2, Fig. 3) and neonatally NGF-treated animals (the latter recorded at less than 9 weeks of age) are shown. The thresholds of neonatally NGF-treated afferents were shifted to the left such that the mean thresholds is approximately half that in controls (see Table 2 ), and this difference was statistically significant (Kolmogorov-Smirnov, $p<0.001$ ). The cumulative sum plot indicates that the distribution of thresholds is similar after neonatal NGF treatment as the curve has approximately the same shape. $B$ shows the same control data compared with the data from neonatally NGF-treated animals recorded when they were older than 9 weeks. The distribution of thresholds approaches that seen in controls and is not significantly different (Kolmogorov-Smirnov, $p=0.32$ ). The number of threshold determinations (number of fibers) used to generate each plot is indicated on each plot. Note that the number of such determinations does not always equal the number of units isolated, as thresholds were sometimes not obtained for technical reasons.

mechanical stimuli. The average receptive field size of H'TMRs in these NGF-treated animals was not significantly different from controls (Table 2). Thus, the action of nconatally administered NGF in sensitizing the A $\delta$ HTMR population to mechanical stimuli appears not to be permanent although the effect considerably outlasts the treatment. 
Table 2. Physiology of slowly adapting HTMRs after NGF treatments

\begin{tabular}{|c|c|c|c|c|c|c|c|}
\hline & Control & Control & $\begin{array}{l}\text { Neonatal } \\
\text { NGF } \\
(0-2 \text { weeks })\end{array}$ & $\begin{array}{l}\text { Neonatal } \\
\text { NGF } \\
(0-2 \text { weeks })\end{array}$ & $\begin{array}{l}\text { Juvenile } \\
\text { NGF } \\
\text { (2-5 weeks) }\end{array}$ & $\begin{array}{l}\text { Juvenile } \\
\text { NGF } \\
(2-5 \text { weeks) }\end{array}$ & $\begin{array}{l}\text { Adult } \\
\text { NGF } \\
(1-4 d)\end{array}$ \\
\hline Age at recording & $<9$ weeks & $>9$ weeks & $<9$ weeks & $>9$ weeks & 5 weeks & 8 weeks & 5 weeks \\
\hline \multicolumn{8}{|l|}{ Slowly adapting HTMR } \\
\hline Mean threshold (gm) & $4.6+3.3$ & $5.1+2.6$ & $2.5 \pm 1.2^{*}$ & $3.8 \pm 2.2$ & $5.6 \pm 2.7$ & $4.2 \pm 2.1$ & $5.5 \pm 3.0$ \\
\hline \multicolumn{8}{|l|}{ Slowly adapting HTMR } \\
\hline Mean receptive field size $\left(\mathrm{mm}^{2}\right)$ & $28.4 \pm 16.2$ & $26.2 \pm 13.2$ & $24.8 \pm 8.9$ & $21.6 \pm 8.2$ & $19.6 \pm 8.8$ & $23.7 \pm 10.5$ & $28.7 \pm 11.5$ \\
\hline
\end{tabular}

* Significantly different from controls $(p<0.001)$.

\section{$N G F$-induced hyperalgesia in "juveniles"}

Animals were treated with NGF from the end of the second postnatal week until 5 weeks of age. It can be seen from Figure 2 that this treatment starts when the threshold of the flexion reflex is still lower than in the mature animal. Like neonatal NGF this treatment appeared to lead to a small reduction in reflex threshold in the first 2 weeks of treatment (nested ANOVA, $p<0.05$ ). The treatment (like neonatal treatment) also had the effect of delaying the normal increase in threshold seen in normal animals over the same period (Fig. 2). Thus, NGF administered to the juvenile rat leads to a hyperalgesia in the mature animal (6-7 weeks). However, after the NGF treatment ceases, mechanical thresholds start to return to normal within 3 weeks (Fig. 2). In contrast, when animals were treated neonatally, recovery occurred only 6 weeks after the treatment ended. This difference might be because of the lower dose used for the juvenile treatment $(1 \mu \mathrm{g} / \mathrm{gm}$ compared with $2 \mu \mathrm{g} / \mathrm{gm}$ used in the neonatal treatment). Despite this difference in recovery times the degree of hyperalgesia after juvenile NGF resembles that found after neonatal NGF; behavioral thresholds of 6-weekold animals were around $10 \%$ of control.

\section{Physiology of A $\delta$ afferents after NGF in "juveniles"}

Recordings were made from $\mathrm{A} \beta$ and $\mathrm{A} \delta$ afferents in juvenile NGF-treated animals at two separate time points. The first was at the point when the treatment ceased ( 5 weeks); these animals $(n=3)$ were markedly hyperalgesic. The second group was recorded from 3 weeks after the NGF treatment ceased. The behavioral thresholds of animals in the latter group $(n=2)$ had begun to approach those found in control animals, although the difference was still significant $(64 \pm 20 \mathrm{gm}$ compared to $168 \pm$ $69 \mathrm{gm}$ in control animals; $p<0.05$, nested ANOVA).

The small number of $A \beta$ afferents that were recorded appeared to be indistinguishable from those found in controls (see Table 1). Thus, the range of afferent types, their physiology and conduction velocity were essentially the same as found in control animals. As in animals treated with anti-NGF from 2 to 5 weeks of age, the relative proportions of A $\delta$ HTMRs, D-hairs, and deep afferents in juvenile NGF-treated animals appeared to be
Figure 5. Cumulative sum distributions of slowly adapting HTMR thresholds after NGF treatment of juvenile and adult rats (see Materials and Methods). The distributions of HTMR thresholds found in juvenile and adult NGF-treated animals are plotted together with those from controls. It can be seen that the curves superimpose, indicating that these treatments had no effect on HTMR thresholds (Kolmogorov-Smirnov, $p>0.9$ ).

\section{Nociceptor Threshold after "Adult" NGF Treatments}

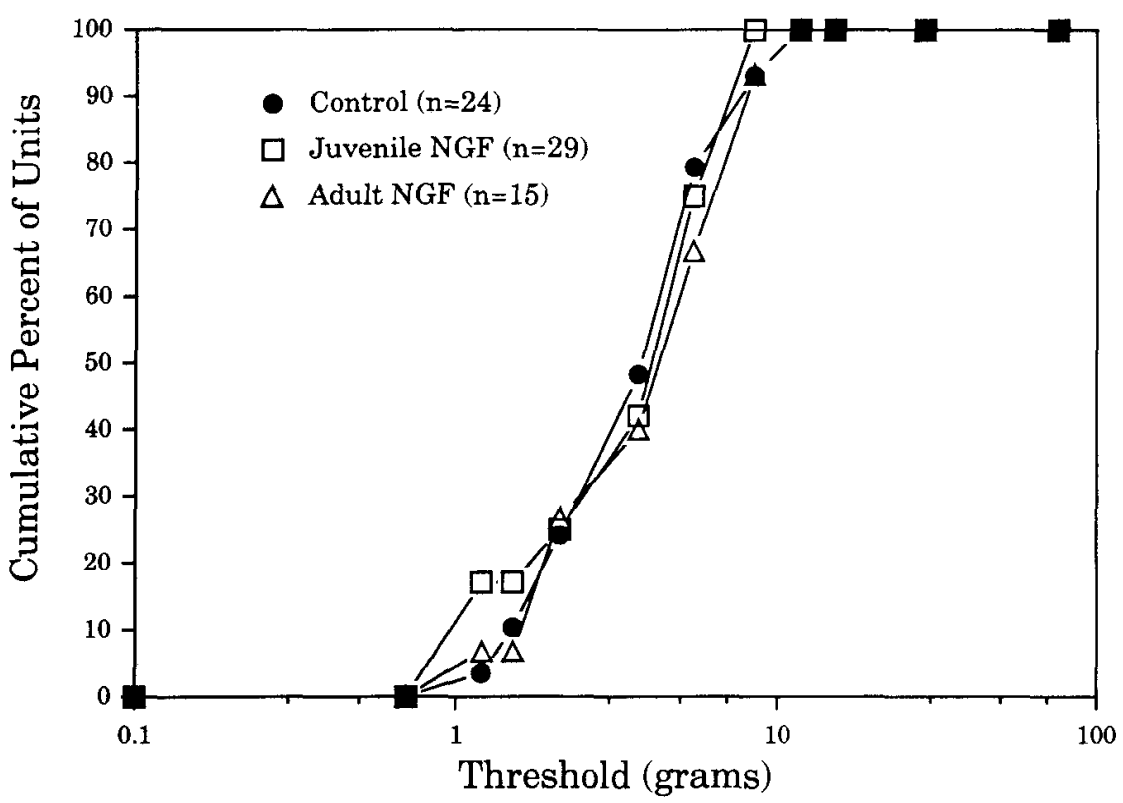




\section{Mechanical Hyperalgesia after Adult NGF}

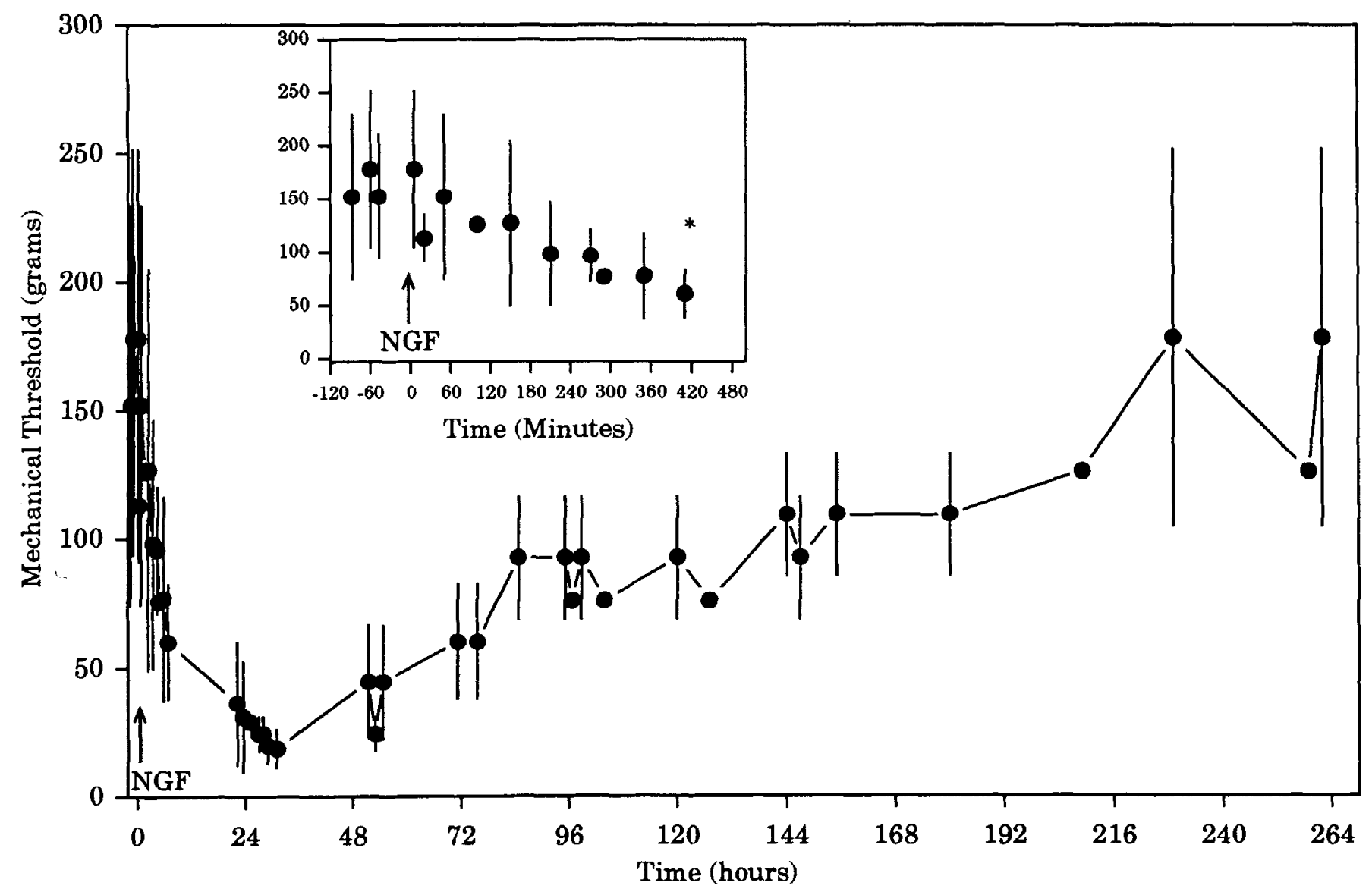

Figure 6. Effects of one NGF injection ( $1 \mu \mathrm{g} / \mathrm{gm}$, i.p.) on the mechanical threshold for paw withdrawal of adult rats (5-6 weeks old). Values are the mean thresholds measured with von Frey hairs; the error bars are SDs. The inset plot shows the same data from 180 min before the injection until $420 \mathrm{~min}$ afterward. It can be seen from the inset that the thresholds appear to fall around 120 min after the injection, but become significantly different only at $420 \mathrm{~min}$ (indicated by asterisk; nested ANOVA, $p<0.05$ ). The main diagram indicates that the decrease in mechanical thresholds appears to last at least $7 \mathrm{~d}$, with the most profound changes apparent $24-48 \mathrm{hr}$ after the injection.

normal; that is, $43 \%$ were HTMRs, $27 \%$ were D-hairs, and $31 \%$ were deep afferents in 5-week-old animals (Ritter et al., 1991; Lewin et al., 1992a). A tolal of 40 high-lhreshold afferents were recorded in both these groups ( 5 and 8 weeks of age), and their properties were essentially no different from one another and from high-threshold afferents found in control animals. Thus, in the two groups, $30 \%$ and $39 \%$ of the HTMRs encountered were rapidly adapting with very high thresholds, and two afferents were recorded for which no receptive field could be found (one in each group) (Fig. $3 E$ ). The mean thresholds of slowly adapting HTMRs in these two groups were similar, and no different from those found in control animals (Table 2). When the thresholds of the afferents from both groups are amalgamated and plotted as a cumulative sum, the curves practically superimpose ( $p>0.9$, Kolmogorov-Smirnov test; Fig. 5). In both juvenile NGF groups the average receptive field size of slowly adapting HTMRs was not significantly different from controls (Table 2; Mann Whitney test, $p>0.7$ ). Thus, after NGF treatment from 2 to 5 weeks of age, rats develop a profound hyperalgesia to mechanical stimuli; however, it is clear that $\mathrm{A} \delta$ nociceptors are not directly affected by the treatment.

\section{Adult NGF treatment-mechanical hyperalgesia}

The interpretation of results obtained with "juvenile" NGF treatment is potentially complicated by the fact that the animals' behavioral thresholds were below adult values when the treatment commenced at 2 weeks (Fig. 2). To avoid this problem, six 5-week-old rats were treated with NGF to determine if their normal behavioral thresholds could be altered. It can be seen from Figure 6 (inset) that the animals' behavioral mechanical threshold had decreased significantly $6.5 \mathrm{hr}$ after the injection $(60.1 \pm 22.2 \mathrm{gm}$ compared to $155.8 \pm 70.3 \mathrm{gm}$ in the control period; $p<0.05$, ANOVA). Twenty-four hours after the initial NGF injection, the mechanical thresholds had dropped further, to between $10 \%$ and $20 \%$ of control, a mechanical hyperalgesia of the same magnitude seen after neonatal or juvenile NGF treatments. The time course of recovery from the single injection of NGF was monitored in three of the animals. Significant mechanical hyperalgesia persisted for at least $3 \mathrm{~d}$, and the animals' mechanical threshold returned to control values after $7 \mathrm{~d}$ (Fig. 6). In the three remaining animals, further NGF injections were given every $24 \mathrm{hr}$ for up to $4 \mathrm{~d}$. At the end of this period the 


\section{Heat Hyperalgesia after Adult NGF}

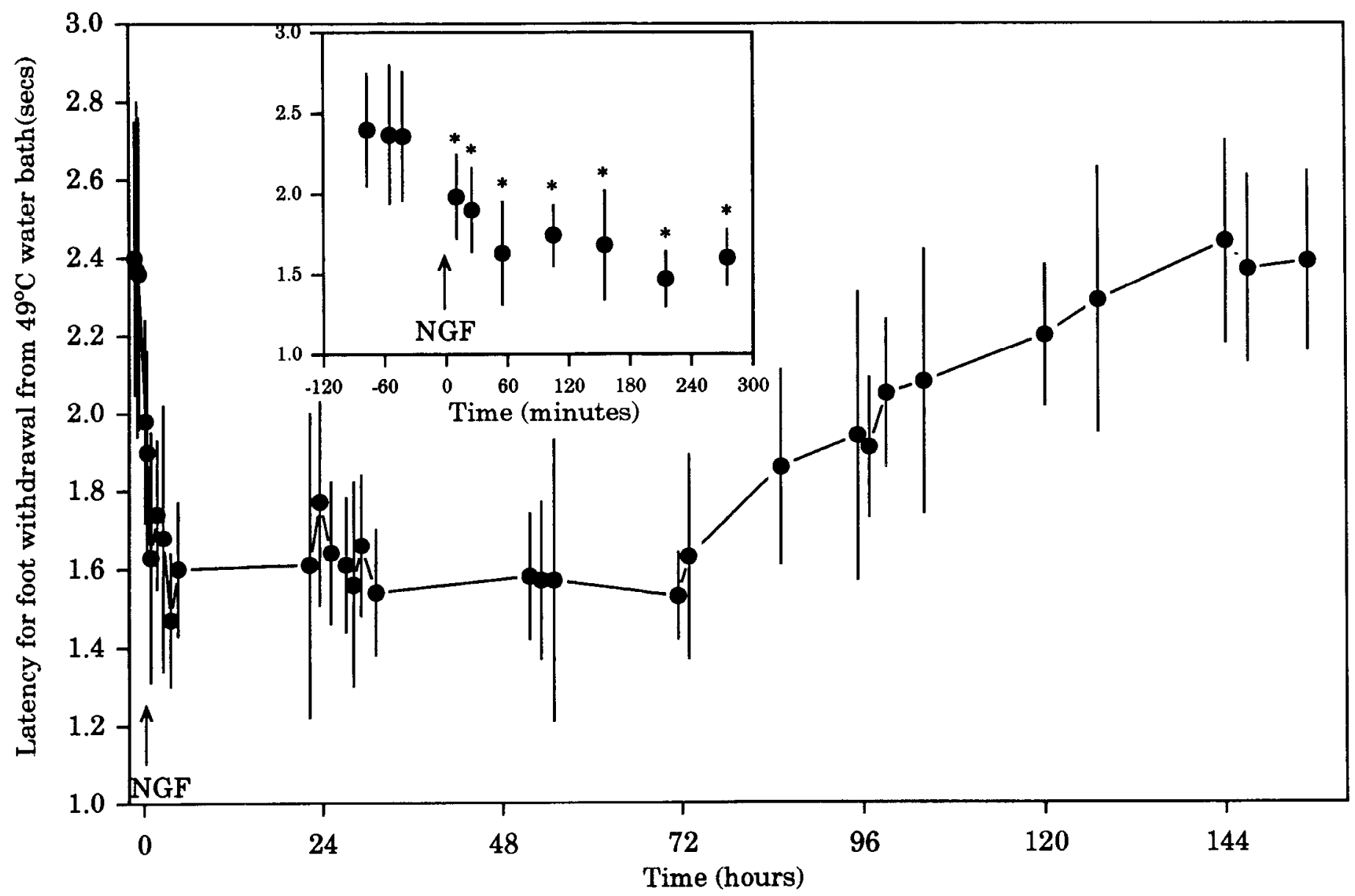

Figure 7. Effects of one NGF injection ( $1 \mu \mathrm{g} / \mathrm{gm}$, i.p.) on the sensitivity of adult rats (5-6 weeks old) to noxious heat. Values are the mean latencies for paw withdrawal from a $49^{\circ} \mathrm{C}$ water bath. The error bars are SDs. The inset plot shows the same data from 120 min before the injection until $300 \mathrm{~min}$ afterward. It can be seen from the inset that the latencies appear to fall almost immediately after the injection (first point is 10 min after the injection) and the first measurement was significantly different from those taken in the control period (nested ANOVA, $p<0.05$; asterisks). The main diagram indicates that the decrease in latency appears to be maximal for at least $3 \mathrm{~d}$, after which it begins to return to control values.

animals ( $4 \mathrm{~d} \mathrm{NGF)} \mathrm{were} \mathrm{prepared} \mathrm{for} \mathrm{acute} \mathrm{electrophysiological}$ experiments to record from single $\Lambda \delta$ afferents (see below). The subsequent doses of NGF did not further reduce the mechanical thresholds (reflex threshold averaged $26.9 \pm 30.9 \mathrm{gm}$ at $24 \mathrm{hr}$ compared to $21.9 \pm 6.9 \mathrm{gm} 4 \mathrm{~d}$ later), but the hyperalgesia was maintained.

\section{Physiology of Ad afferents after adult NGF treatment}

In the three animals studied, recordings were made from a total of $29 \mathrm{~A} \delta$ nociceptors. Of these, $16(55 \%)$ were the slowly adapting type, $10(35 \%)$ were rapidly adapting, and a receptive field could not be found for 3 units $(10 \%)$ (Fig. $3 F$ ). The mean threshold of slowly adapting HTMRs in these animals was not significantly different from those in control animals, as can be seen from Figure 5 (Kolmogorov-Smirnov, $p>0.9$ ). The mean receptive field size of these afferents was not significantly different than that found in controls (Table $2 ; p>0.9$, Mann-Whitney test). Therefore, NGF treatment of mature animals appears to produce a substantial and profound mechanical hyperalgesia without affecting the physiology of A $\delta$ nociceptive afferents. In this group of animals, no change was seen in the proportion of HTMRs.

\section{Thermal hyperalgesia after NGF treatment}

Animals treated with NGF over a period spanning the neonatal and juvenile periods ( $0-5$ weeks) displayed a substantial hyperalgesia to noxious heat (Fig. 1). It was not clear to what extent this reflected NGF treatment in neonates or adults. However, the effects of NGF on heat nociception were tested in more detail in adult NGF-treated animals (one to four daily NGF injections) (Fig. 7). It can be seen that $15 \mathrm{~min}$ after the first injection of NGF the latency for foot withdrawal was significantly reduced $(1.98 \pm 0.07 \mathrm{sec}$ compared to $2.37 \pm 0.05 \mathrm{sec}$; nested ANOVA, $p<0.01)$. This thermal hyperalgesia was fully developed $50 \mathrm{~min}$ after the injection; latencies were on average around $33 \%$ shorter than in the control period, and this decrease was highly significant (nested ANOVA, $p<0.001$ ). This hyperalgesia remained quantitatively the same for $3 \mathrm{~d}$ after the injection (Fig. 7). On the third day the hyperalgesia appeared to wear off slowly such that the latency for foot withdrawal had returned to normal $7 \mathrm{~d}$ after the NGF injection. 


\section{Threshold for Foot Withdrawal after Neonatal Anti-NGF Treatment}

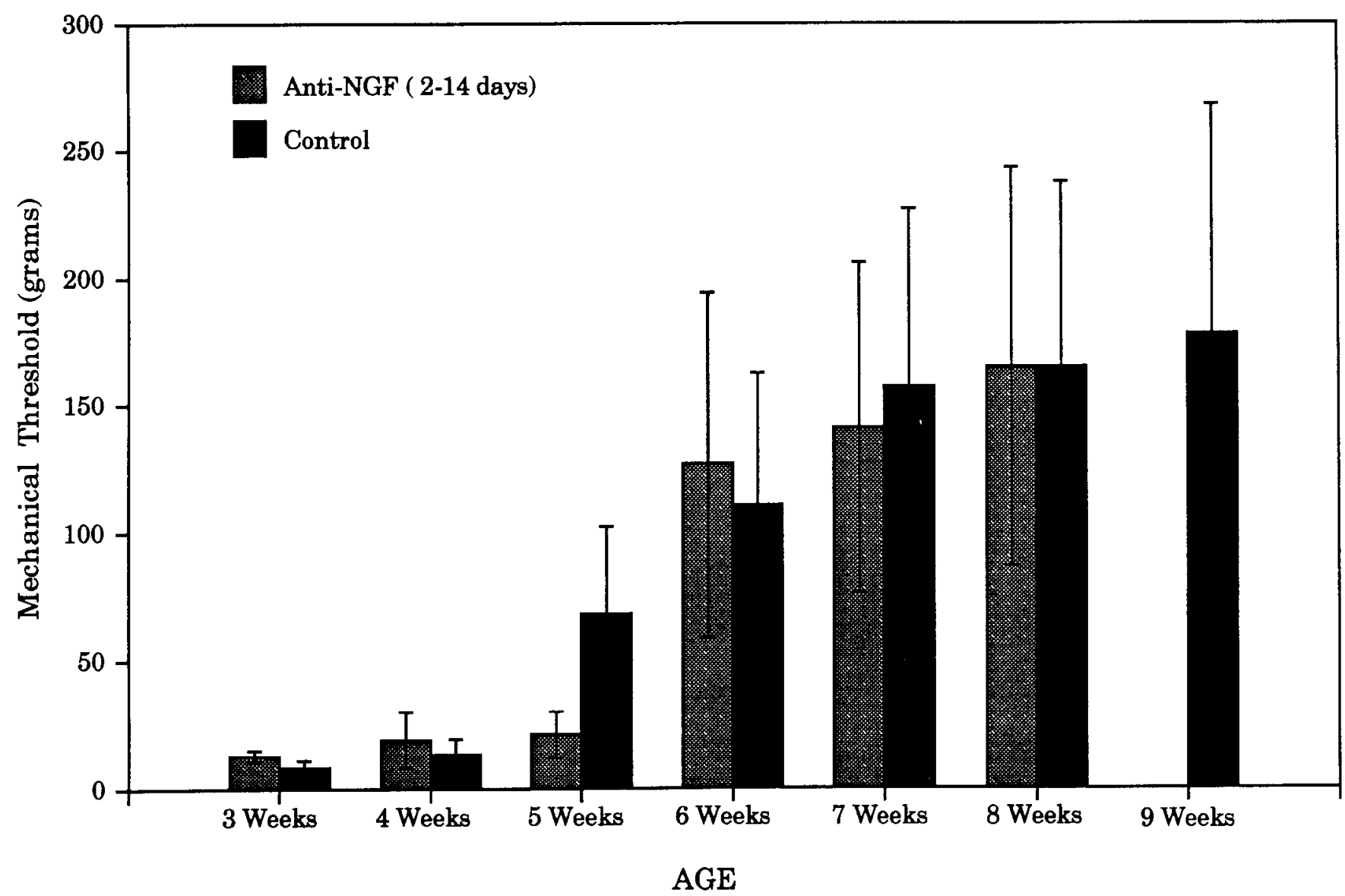

Figure 8. Serial behavioral measurements made in rats aged 3-9 weeks after neonatal anti-NGF treatment from 2 to $14 \mathrm{~d}$ (a treatment that does not produce sensory neuron death; Lewin et al., 1992a). Measurements of mechanical thresholds were made every day (see Materials and Methods), and the data from each group were averaged for the week. It can be seen that compared to controls (solid bars), nconatal anti-NGF treatment (crosshatched bars) does not produce any significant change (nested ANOVA, $p>0.5$ ) in the animals' mechanical threshold at any point (up to 9 weeks of age) after the treatment ends. Error bars are SDs.

\section{Effects of anti-NGF on flexion reflex threshold}

Recently, we found that A $\delta$ nociceptors are highly dependent on the availability of NGF during the first 2 postnatal weeks in the rat (Ritter et al., 1991; Lewin et al., 1992a). In light of the findings with NGF described above, we have tested the behavioral thresholds of animals treated with anti-NGF from PND 2 to PND 14 to ascertain if the subsequent loss of A $\delta$ HTMRs had consequences for the animals' behavior. It can be seen from Figure 8 that the mechanical thresholds of these animals were indistinguishable from those of controls from the third to the ninth postnatal week (see Discussion).

\section{Discussion}

Here we have described a hyperalgesic syndrome in rats brought about by the systemic administration of the neurotrophic protein NGF. The mechanical hyperalgesia is very profound but is highly specific, there being no evidence that innocuous stimuli such as touch or brush lead to pain; that is, there is no allodynia. In normal adult rats the stimuli needed to evoke the nociceptive flexion reflex is an order of magnitude higher than the thresholds of individual mechanical nociceptors (Woolf, 1983). This indicates that central summation of nociceptive activity is needed to provoke the perception of pain. The flexion reflex threshold can be reduced by up to $90 \%$ after NGF treatment, but the reduced stimuli evoking the reflex after NGF are still within the noxious range in that they are sufficient to activate most normal mechanical nociceptors. These considerations lead us to conclude that NGF treatment produces mechanical hyperalgesia. Mechanical hyperalgesia in experimental animals and humans is observed almost always after inflammatory or nerve lesions and has been postulated to be due primarily to changes in the central processing of sensory inputs (Hardy et al., 1950; Woolf, 1983; McMahon and Wall, 1984; Hylden et al., 1989; LaMotte et al., 1991). In these experiments we have shown that one protein, NGF, may reproduce such a hyperalgesia in the absence of any injury or inflammation.

Using the same behavioral measures, we were unable to detect any difference in the flexion reflex threshold after neonatal antiNGF treatment. This is surprising in light of the very dramatic 
changes that take place in the character of the skin innervation after neonatal anti-NGF treatment. Most myelinated nociceptors appear to be converted into low-threshold D-hairs, and the remaining nociceptors have elevated mechanical thresholds (Ritter et al., 1991; Lewin et al., 1992a). One might have anticipated hyperalgesia or even allodynia if these peripheral changes alone had occurred. The absence of detectable behavioral consequences suggests that central adjustments take place after neonatal anti-NGF treatments. Indeed, preliminary data indicate that central neurons that normally receive significant synaptic input from $A \delta$ nociceptors have altered receptive field properties after neonatal anti-NGF treatment (G. R. Lewin and L. M. Mendell, unpublished observations). In contrast, the NGF treatments used here did not lead to changes in the proportion of A $\delta$ nociceptors present, and so we assume that no rearrangement in the central connections of A $\delta$ nociceptors had taken place.

The mechanical hyperalgesia resulting from NGF treatment involves at least two separate mechanisms. Neonatal NGF treatment led to hyperalgesia in adult animals that was accompanied by a long-lasting sensitization of $A \delta$ fibers to mechanical stimuli. In contrast, NGF treatments given to animals after PND 14 (juvenile and adult treatments) produced a quantitatively similar mechanical hyperalgesia in the absence of any detectable sensitization of A $\delta$ nociceptors. The possible mechanisms underlying these two hyperalgesic states are discussed below.

The long-lasting sensitization of $\mathrm{A} \delta$ nociceptors induced by neonatal NGF treatment had a time course that paralleled that of the bchavioral hypcralgesia (Figs. 2-4). We have taken this as good evidence that the hyperalgesic syndrome in this case was caused by the peripheral sensitization of A $\delta$ nociceptive fibers. Further evidence for this assertion comes from recent experiments where we found that the mechanical thresholds of unmyelinated afferents in these animals are not greatly affected by the NGF treatment (Lewin and Mendell, unpublished observations). It remains possible, however, that neonatal NGF treatment also led to a long-lasting change in the central processing of nociceptive information from skin that contributed to the hyperalgesia.

The mechanism by which NGF sensitizes A $\delta$ nociceptors in these experiments is unknown. It is likely that NGF is highly concentrated in the epidermis (Davies et al., 1987), where the endings of $A \delta$ nociceptors may normally reside (Kruger et al., 1981). These epidermal endings may be particularly sensitive to any incrcasc in the availability of NGF during this time, particularly inasmuch as the critical period for NGF in stabilizing HTMR innervation of the skin occurs from PND 4 to PND 11 (Lewin et al., 1992a). NGF has been demonstrated to facilitate the local proliferation of some sympathetic nerve terminals in vivo (Hill et al., 1988; Edwards et al., 1989). If, analogously, the number of epidermal endings per sensory fiber increased in response to excess NGF, a decrease in mechanical threshold might occur as a given stimulus would impinge on more transduction sites. This may also account for the reversible loss of mechanically insensitive fibers after neonatal NGF treatment. We observed no significant increase in the receptive field area of afferents in NGF-treated animals, suggesting that new terminals or sprouts were only formed within the normal terminal field. An analogous situation may be CNS sprouting where neurons rarely elaborate sprouts outside their normal innervation territory (reviewed in Raisman and Field, 1990; Mendell and Lewin, 1992). The sprouting model outlined above does not, of course, explain why the sensitization of the A $\delta$ fibers wears off. After the treatment ceases, NGF is still synthesized in the tissue, but this endogenous NGF may be sufficient to maintain sprouts only for several weeks.

In these experiments we never observed single $A \delta$ units in the sural nerve with receptive fields outside the normal innervation territory of the nerve after NGF treatments. This is in contrast to the findings of Diamond et al. (1992), who, using a nociceptive reflex, obtained evidence that NGF might promote the de novo collateral sprouting of nociceptive fibers in adult rat trunk skin. The systemic doses of NGF used in adult animals in these expcriments were smaller than those administered locally by Diamond et al. (1992), and thus may have been insufficient to promote such sprouting. Alternatively, the profound mechanical hyperalgesia after NGF (which would increase the gain of nociceptive reflexes) might have increased the apparent size of the nerve distribution assessed by the reflex testing used by Diamond et al. (1992), as stimulation of afferents at the edge of the nerve distribution might become newly capable of eliciting the reflex. Thus, the idea that NGF may regulate the collateral sprouting of sensory axons in skin requires further examination.

We cannot exclude the possibility that neonatal NGF treatment leads to a hypertrophy of the sympathetic nervous system, the overactivity of which in turn sensitizes primary afferents in the periphery. However, the available evidence indicates that interactions between sympathetic neurons and primary afferents only occur after nerve or tissue injury (Levine et al., 1986; Habler et al., 1987; Sato and Perl, 1991).

In more mature animals we have demonstrated that both a mechanical and thermal hyperalgesia can result from NGF treatment. The mechanical hyperalgesia occurs in the absence of any change in the physiology of A $\delta$ fibers when NGF is given to animals from 2 to 5 weeks or over $4 \mathrm{~d}$ in adulthood. It may be that under these circumstances NGF sensitizes unmyelinated afferents to inechanical stimuli. At present we have no evidence on this point. If, however, NGF did act to sensitize sensory neurons in the periphery to mechanical stimuli, one might expect to see a rapid decrease in mechanical threshold following systemic or local application. We did not observe any such rapid changes in these experiments. The earliest point at which a mechanical hyperalgesia became statistically significant was over $6 \mathrm{hr}$ after the injection. It might be argued that small changes in threshold occurred acutely in these experiments, but we could not detect them until over $6 \mathrm{hr}$ after the injection. One other group has applied NGF directly into the foot and observed no change in mechanical threshold acutely using the Randall-Siletto paw withdrawal test (Taiwo et al., 1991), which is more sensitive to small-threshold changes. The time course of the mechanical hyperalgesia therefore appears to be too slow for a peripheral sensitizing effect of NGF; however, we cannot exclude this possibility directly.

Another mechanism, besides peripheral sensitization, by which NGF-induced mechanical hyperalgesia might arise is by upregulation of the central connectivity of nociceptive afferents. This idea has received independent experimental support. Thus, when excess NGF is applied to the peripheral targets of some afferents in adult animals, these afferents expand their central discharge zone (Lewin et al., 1992b), possibly as a result of changes triggered by NGF-induced upregulation of certain neuropeptides (see introductory remarks). This model may be used to explain 
the hyperalgesia produced by the systemic NGF treatments given here. Although we have not shown here that NGF binds to its receptor in the periphery, it is unlikely that it could gain access to the CNS directly in adult animals; thus, we believe it is probably acting via its high-affinity receptor located on peripheral sensory neurons (Davies et al., 1987). The time course of the effect is, however, too fast for the action of NGF to be restricted to high-affinity receptors in the skin. Recent evidence indicates that systemic NGF may well act on functional receptors all along the peripheral axon including perhaps the cell body in the DRG (DiStefano et al., 1992). Thus, a systemic dose of NGF might well upregulate peptides in NGF-responsive sensory neurons within minutes after an injection. These peptides could then be transported to the central terminals within hours by fast axonal transport.

The effects of NGF on heat nociception in adult animals stand in marked contrast to those on mechanical nociception. Within 15 min of the NGF injection (Fig. 8) the animals displayed a marked heat hyperalgesia. This time course is incompatible with a mechanism requiring fast axonal transport from the cell body to the central terminals. Instead, it strongly suggests that NGF can lead to the sensitization of the receptors of certain unmyelinated afferents to heat. The heat hyperalgesia was very longlasting, and so the later phases of this response may be due to changes in the central processing of nociceptive input as well. It is known that high-affinity NGF receptors are present on mast cells, and their activation can lead to mast cell degranulation (Mazurek et al., 1986). Thus, the presence of high concentrations of NGF may well lead to the release of substances that can sensitize primary afferents to heat. Alternatively, it might be argued that mast cell degranulation resulting from the treatment leads to changes in the thermal conductivity of the skin (perhaps by changes in blood flow) and this might then lead to shorter foot withdrawal latencies. However, we observed no obvious erythema in the foot at any point after the injection. Indeed, the long time course of the effect suggests that transient changes in blood flow are unlikely to be responsible for the change.

The model of NGF's central actions outlined above in the adult animal may be represent a physiological mechanism that normally operates under conditions where animals are subject to injury. It is known, for example, that NGF production is greatly increased in inflamed tissue (Weskamp and Otten, 1987), and may be responsible for the upregulation of neuropeptide seen after inflammation (Donnerer et al., 1992). In this way the peripheral elevation of NGF might lead to the maintenance of a hyperalgesia of peripheral and central origin for several days. The hyperalgesia that results might have adaptive advantages as it forces the organism to guard the affected part so that healing might proceed more rapidly. In summary, we have provided evidence that NGF may fulfill two quite different roles for nociceptive neurons in neonatal and adult animals. Despite the change in NGF mode of action from development to adulthood, the consequences of elevating this protein on the animals behavior appears to remain the same. Furthermore, the results highlight a potentially important physiological role for NGF in the maintenance of pathological pain states in adult animals.

\section{References}

Aloe L, Cozzari C, Calissano P, Levi-Montalcini R (1981) Somatic and behavioral post-natal effects of fetal injections of nerve growth factor antibodies in the rat. Nature 291:413-415.
Barde Y-A (1989) Trophic factors and neuronal survival. Neuron 2:1525-1534.

Burgess PR, Perl ER (1967) Myelinated afferent fibers responding specifically to noxious stimulation of skin. J Physiol (Lond) 190:541562.

Burgess PR, Perl ER (1973) Cutaneous mechanoreceptors and nociceptors. In: Handbook of sensory physiology, Vol 2 (Iggo A, ed), pp 29-78. Berlin: Springer.

Davies AM, Bandtlow C, Heumann R, Korsching S, Rohrer H, Thoenen $H$ (1987) Timing and site of nerve growth factor synthesis in developing skin in relation to innervation and expression of the receptor. Nature 326:353-358.

Diamond J, Holmes M, Coughlin M (1992) Endogenous NGF and nerve impulses regulate the collateral sprouting of sensory axons in the skin of the adult rat. J Neurosci 12:1454-1466.

DiStefano PS, Friedman B, Radziewjewski C, Alexander C, Boland P, Schick CM, Lindsay RM, Wiegand SJ (1992) The neurotrophins BDNF, NT-3 and NGF display distinct patterns of retrograde axonal transport in peripheral and central neurons. Neuron 8:983-993.

Donnerer J, Schuligoi R, Stein C (1992) Increased content and transport of substance $P$ and calcitonin gene-related peptide in sensory nerves innervating inflamed tissue: evidence for a regulatory function of nerve growth factor in vivo. Neuroscience 49:693-698.

Edwards RH, Rutter WJ, Hanahan D (1989) Directed expression of NGF to pancreatic $\beta$ cells in transgenic mice leads to selective hyperinnervation of the islets. Cell 58:161-170.

Fcrrcira SH, Lorenzetti BB, Correa FMA (1978) Central and peripheral analgesic action of aspirin-like drugs. Eur J Pharmacol 53:3948.

Fitzgerald M (1987) Cutaneous primary afferent properties in the hindlimb of the neonatal rat. J Physiol (Lond) 383:79-82.

Fitzgerald M, Shaw A, Macintosh N (1988) Post-natal development of the cutaneous flexor reflex: a comparative study of infants and newborn rat pups. Dev Med Child Neurol 30:520-526.

Fitzgerald MJT (1967) Perinatal changes in epidermal innervation in rat and mouse. J Comp Neurol 126:37-42.

Fulton BP (1987) Post-natal changes in conduction velocity and somal action potential parameters of rat dorsal root ganglion neurons. Neurosci Lett 73:125-130.

Goedert M, Stoeckel K, Otten U (1980) Biological importance of the retrograde axonal transport of nerve growth factor in sensory neurons. Proc Natl Acad Sci USA 78:5895-5898.

Goedert M, Otten U, Hunt SP, Bond A, Chapman D, Schlumpf M, Lichtensteiger W (1984) Biochemical and anatomical effects of antibodies against nerve growth factor on developing rat sensory ganglia. Proc Natl Acad Sci USA 81:1580-1584.

Gorin PD, Johnson EM Jr (1980) Effects of long term nerve growth factor deprivation on the nervous system of the rat: an experimental autoimmune approach. Brain Res 198:27-42.

Habler H-J, Janig W, Koltzenburg M (1987) Activation of unmyelinated afferents in chronically lesioned nerves by adrenaline and excitation of sympathetic efferents in the cat. Neurosci Lett 82:35-40.

Handwerker HO, Kilo S, Reeh PW (1991) Unresponsive afferent nerve fibres in the sural nerve of the rat. J Physiol (Lond) 435:229-242.

Hardy JD, Wolff HG, Goodell H (1950) Experimental evidence on the nature of cutaneous hyperalgesia. J Clin Invest 29:115-140.

Hill CE, Jelinek H, Hendry IA, McLennen IS, Rush RA (1988) Destruction by anti-NGF of autonomic sudomotor neurones and subsequent hyper-innervation of the foot pad by sensory fibers. J Neurosci Res 19:474-482.

Hulsebosch CE, Perez-Polo JR, Coggeshall RE (1987) In vivo antiNGF induces sprouting of sensory axons in dorsal roots. J Comp Neurol 259:445-451

Hylden JL, Nahin RL, Traub, RJ, Dubner R (1989) Expansion of receptive fields of spinal lamina $I$ projection neurons in rats with unilatcral adjuvant-induced inflammation: the contribution of dorsal horn mechanisms. Pain 37:229-243.

Inaishi Y, Kashihara Y, Sakaguchi M, Nawa H, Kuno M (1992) Cooperative regulation of calcitonin gene-related peptide levels in rat sensory neurons via their central and peripheral processes. J Neurosci $12: 518-524$.

Johnson EM Jr, Gorin PD, Brandeis LD, Pearson J (1980) Dorsal root ganglion neurons are destroyed by exposure in utero to maternal antibody to nerve growth factor. Science $210: 916-918$. 
Johnson EM Jr, Rich KM, Yip HK (1986) The role of NGF in sensory neurons in vivo. Trends Neurosci 9:3-37.

Kessler JA, Black IB (1980) Nerve growth factor stimulates the development of substance $\mathbf{P}$ in sensory ganglia. Proc Natl Acad Sci USA 77:649-652.

Koerber HR, Druzinsky RE, Mendell LM (1988) Properties of somata of spinal dorsal root ganglion cells differ according to peripheral receptor innervated. J Neurophysiol 60:1584-1596.

Kress M, Koltzenburg M, Reeh PW, Handwerker HO (1992) Responsivencss and functional attributes of electrically localized terminals of cutaneous C-fibres in vivo and in vitro. J Neurophysiol 68 : 581-596.

Kruger L, Perl ER, Sedivec MJ (1981) Fine structure of myelinated mechanical nociceptor endings in cat hairy skin. J Comp Neurol 198: 137-154.

LaMotte RH, Shain CJ, Simone DA, Tsai E-FP (1991) Neurogenic hyperalgesia: psychophysical studies of underlying mechanisms. J Neurophysiol 66:190-211.

Leah JD, Cameron AA, Snow PJ (1985) Neuropeptides in physiologically identified mammalian sensory neurones. Neurosci Lett 56:257264.

Levine JD, Taiwo YO, Collins SD, Tam JK (1986) Noradrenaline hyperalgesia is mediated through interaction with sympathetic postganglionic neuronc terminals rather than activation of primary afferent nociceptors. Nature 323:158-160.

Lewin GR, McMahon SB (1991) Physiological properties of primary sensory neurons appropriately and inappropriately innervating skin in adult rats. J Neurophysiol 66:1205-1217.

Lewin GR, Mendell LM (1992) NGF induced heat and mechanical hyperalgesia in adult rats. Soc Neurosci Abstr 18:60.8.

Lewin GR, Ritter AM, Mendell LM (1991) Regulation of nociceptor function by NGF in neonatal and adult rats. Soc Neurosci Abstr 17: 546.3.

Lewin GR, Ritter AM, Mendell LM (1992a) On the role of NGF in the development of myelinated nociceptors. J Neurosci 12:18961905.

Lewin GR, Winter J, McMahon SB (1992b) Regulation of afferent connectivity in the adult spinal cord by nerve growth factor. Eur $\mathbf{J}$ Neurosci 4:700-707

Lewin GR, Lisney SJW, Mendell LM (1992c) Neonatal anti-NGF treatment reduces the $A \delta$ and $C$-fibre evoked vasodilatator responses in rat skin: evidence that nociceptor afferents mediate antidromic vasodilatation. Eur J Neurosci 4:1213-1218.

Lindsay RM (1988) The role of neurotrophic factors in development, maintenance and regeneration of sensory neurons. In: The making of the nervous system (Parnavelas J, Stern CD, Stirling RV, eds), pp 148-165. New York: Oxford UP.

Lindsay RM, Lockett C, Sternberg J, Winter J (1989) Neuropeptide expression in cultures of adult sensory neurons: modulation of substance $\mathbf{P}$ and CGRP levels by nerve growth factor. Neuroscience 33 : 53-65.

Lynn B, Carpenter SE (1982) Primary afferents from the hairy skin of the rat hindlimb. Brain Res 238:29-43.

Mazurek N, Weskamp G, Erne P, Otten U (1986) Nerve growth factor induces mast cell degranulation without changing intracellular calcium levels. FEBS Lett 198:315-320.

McMahon SB, Wall PD (1984) Receptive fields of lamina I projection cells move to incorporate a nearby area of injury. Pain 19:235-247.

Mendell LM, Lewin GR (1992) Removing constraints on neural sprouting. Curr Biol 2:259-262.

Meyer RA, Davies KD, Cohen RH, Treede R-D, Campbell JN (1991) Mechanically insensitive afferents (MIAs) in cutaneous nerves of monkeys. Brain Res 561:252-261.

Otten U (1984) Nerve growth factor and the peptidergic sensory neurons. Trends Pharmacol 5:307-310.
Otten U, Lorez HP (1983) Nerve growth factor increases substance $\boldsymbol{p}$ rholecystokinin and vasoactive intestinal polypeptide immunoreactivities in primary sensory neurones of newborn rats. Neurosci Lett 34:153-158.

Otten U, Goedert M, Mayer N, Lembeck F (1980) Requirement of nerve growth factor for the development of substance P containing neurones. Nature 287:158-159.

Otten U, Lorez HP, Businger F (1983) Nerve growth factor antagonizes the neurotoxic action of capsaicin on primary sensory neurones. $\mathrm{Na}$ ture 301:515-517.

Raisman G, Field FM (1990) Synapse formation in the adult brain after lesions and after transplantation of embryonic tissue. J Exp Biol 153:277-289.

Reynolds ML, Fitzgerald M, Benowitz LI (1991) GAP-43 expression in developing cutaneous and muscle nerves in the rat hindlimb. Neuroscience $41: 200-211$.

Ritter AM, Mendell LM (1992) The somal membrane properties of physiologically identified sensory neurons in the rat: effects of nerve growth factor. J Neurophysiol 68:2033-2041.

Ritter AM, Lewin GR, Kremer NE, Mendell LM (1991) Requirement for nerve growth factor in the development of myelinated nociceptors in vivo. Nature 350:500-502.

Ritter AM, Lewin GR, Mendell LM (1993) Regulation of myelinated nociceptor function by nerve growth factor in neonatal and adult rats Brain Res Bull, in press.

Rose RD, Koerber HR, Sedivec MJ, Mendell LM (1986) Somal action potential duration differs in identified primary afferents. Neurosci Lett 63:259-264.

Sato J, Perl ER (1991) Adrenergic excitation of cutaneous pain receptors induced by peripheral nerve injury. Science 251:1608-1610.

Schenker A, Mobley WC, Shooter EM (1976) Isolation of nerve growth factor. Biochemistry 15:5543-5552.

Schwartz JP, Pearson J, Johnson EM Jr (1982) Effect of exposure to anti-NGF on sensory neurons of adult rats and guinea pigs. Brain Res 244:378-381.

Stockel K, Schwab M, Thoenen H (1975) Specificity of retrograde transport of nerve growth factor in sensory neurons. A biochemical and morphological study. Brain Res 89:1 14.

Taiwo YO, Levine JD, Burch RM, Woo JE, Mobley WC (1991) Hyperalgesia induced in the rat by the amino-terminal octapeptide of nerve growth factor. Proc Natl Acad Sci USA 88:5144-5148.

Thoenen H, Barde Y (1980) Physiology of nerve growth factor. Physiol Rev 60:1284-1335.

Tonra JR, Lewin GR, McMahon SB, Mendell LM (1992) Rearrangement of CGRP-IR fibers in skin following neonatal anti-NGF treatment. Soc Neurosci Abstr 18:60.10.

Urschel BA, Brown PB, Hulsebosch CE (1991) Differential effects on sensory processes and behavioral alterations in the rat after treatment with anti-bodies to nerve growth factor. Fxp Neurol 114:44-52

Verge VMK, Richardson PM, Benoit R, Riopelle RJ (1989) Histochemical characterization of sensory neurons with high-affinity receptors for nerve growth factor. J Neurocytol 18:583-591.

Weskamp G, Otten $U$ (1987) An enzyme-linked immunoassay for nerve growth factor (NGF): a tool for studying regulatory mechanisms involved in NGF production in brain and peripheral tissues. J Neurochem 48:1179-1786.

WoolfCJ (1983) Evidence for a central component of post-injury pain hypersensitivity. Nature 306:686-688.

Yip HK, Rich KM, Lampe PA, Johnson EM (1984) The effects of nerve growth factor and antiserum on the post-natal development and survival after injury of sensory neurons in rat dorsal root ganglia. J Neurosci 4:2986-2992. 